\title{
La deuxième éradication : la peste bovine
}

\section{The second eradication: Rinderpest}

\section{F. Moutou}

Reçu le 30 novembre 2013 ; accepté le 22 janvier 2014

(C) Société de pathologie exotique et Springer-Verlag France 2014

Résumé L'éradication du virus de la peste bovine en 2011 a été célébrée plus discrètement que celle du virus de la variole, mais il s'agit bien du deuxième programme mondial d'éradication d'un virus qui aboutit. Ceci est l'occasion de rappeler l'importance que la peste bovine a pu avoir durant les siècles passés pour l'élevage et pour la santé publique.

Mots clés Peste bovine · Élevage bovin · Campagne de vaccination $\cdot$ Services vétérinaires $\cdot$ Éradication $\cdot$ Histoire

\begin{abstract}
The eradication of rinderpest virus was less celebrated than the eradication of smallpox virus. However, this is only the second campaign to eradicate a virus worldwide which is successful. This gives the opportunity to recall how important rinderpest had been these past centuries for farmers and for public health.
\end{abstract}

Keywords Rinderpest $\cdot$ Cattle farming $\cdot$ Vaccination campaign $\cdot$ Veterinary services $\cdot$ Eradication $\cdot$ History

L'éradication de la variole date maintenant de plus de 40 ans. Depuis, l'OMS a successivement annoncé les probables et prochaines disparitions de plusieurs autres maladies comme le paludisme ou la poliomyélite. Il faut avouer que, fin 2013, les dates possibles d'obtention de ces résultats semblent encore lointaines. Le cas de la poliomyélite mériterait une analyse approfondie tant le but a semblé proche alors qu'aujourd'hui il paraît s'éloigner à nouveau.

Malgré tout, une deuxième maladie a bel et bien été éliminée récemment, mais dans une relative discrétion en dehors des responsables des services de santé animale. L'annonce de l'éradication de la peste bovine a été faite en 2011 conjointement par la FAO (Organisation des Nations Unies pour l'agriculture et l'alimentation, Rome) et l'OIE (Organisation mondiale de la santé animale, Paris). Le 28 juin 2011 lors de l'annonce officielle de l'éradication de la maladie,

F. Moutou $(\bowtie)$

42 , rue de l'Est, 92100 Boulogne-Billancourt

e-mail : francoismoutou@orange.fr
Peter Doherty, prix Nobel de médecine en 1996, a rappelé l'importance de l'évènement, bien au-delà de la seule santé animale. Il s'agit en effet d'une maladie du bétail domestique, essentiellement des ruminants mais son histoire est loin d'être anodine pour l'espèce humaine [6].

La peste bovine n'est pas une inconnue. L'agent responsable est un virus de la famille des Paramyxoviridae et du genre Morbillivirus, très proche de l'agent de la rougeole humaine. Les virologistes admettent que c'est l'adaptation à l'espèce humaine du virus de la peste bovine présent chez l'ancêtre des bovins lors du processus de la domestication qui expliquerait l'origine du virus de la rougeole. Comme l'aurochs (Bos primigenius), ancêtre des bovins domestiques à bosse et sans bosse, a disparu au XVII ${ }^{\mathrm{e}}$ siècle, il ne sera sans doute pas possible de le confirmer définitivement. On peut également remarquer qu'il n'est pas connu d'autres Morbillivirus chez les primates sauvages, même si les grands singes sont réceptifs et sensibles au virus de la rougeole en captivité. D'un point de vue évolutif et adaptatif, le virus de la peste bovine, sous la forme rougeole humaine, a donc survécu à l'extinction de l'aurochs et à celle de son virus.

La peste bovine était la maladie la plus crainte des éleveurs, tant la mortalité pouvait être importante. Oubliée en Europe, elle a pourtant façonné le paysage agricole au cours des siècles. Les vagues épizootiques arrivaient régulièrement des steppes d'Europe centrale vers l'ouest du continent [8]. Le dernier épisode survenu au début du $\mathrm{XX}^{\mathrm{e}}$ siècle est à l'origine de la création de l'OIE à Paris en 1924.

Le réservoir du virus se situait sans doute chez des bovins en Asie. L'Amérique est restée épargnée, mais, à la fin du $\mathrm{XIX}^{\mathrm{e}}$ siècle, un corps expéditionnaire italien a introduit le virus en Afrique au niveau des rivages de l'Abyssinie. Des bovins indiens ont débarqué avec le virus dans le port de Massaoua, aujourd'hui en Erythrée, probablement en 1887. Le bilan a été dramatique. En quelques années l'ensemble du continent a été touché. Toute la faune, ruminants mais aussi suidés, était complètement naïve vis-à-vis de ce virus. Les troupeaux domestiques et sauvages ont été balayés. L'impact humain a été tout aussi violent chez les peuples pasteurs totalement dépendants de leurs troupeaux. 
La lutte contre la peste bovine, dès qu'un vaccin a été mis au point vers le milieu du $\mathrm{XX}^{\mathrm{e}}$ siècle a été un des grands succès de la recherche vétérinaire et des services vétérinaires. Durant toutes les années 1990 et la première décennie du $\mathrm{XXI}^{\mathrm{e}}$ siècle, le programme PACE (programme panafricain de lutte contre la peste bovine et les épizooties) a permis de rechercher de manière coordonnée les dernières zones d'endémie, de les maîtriser et de vérifier régulièrement l'absence du virus dans le réservoir sauvage [1]. Des centaines d'antilopes et de buffles ont été testés pendant des années à travers le continent. Le développement d'un vaccin thermorésistant a représenté une réelle avancée technologique [5]. En effet, garantir la chaîne du froid au vaccin depuis les laboratoires de fabrication jusqu'aux pâturages de troupeaux transhumants était une gageure difficile à tenir.

En Asie, les derniers foyers datent aussi du tout début du $\mathrm{XXI}^{\mathrm{e}}$ siècle et ont été identifiés en Mongolie, en Russie et au Pakistan. L'annonce de l'éradication de la peste bovine a été précédée de plusieurs articles dans des revues scientifiques généralistes $[4,7]$. D'après certains rapports, il aurait été plus facile de vacciner les troupeaux contre la peste bovine y compris dans des pays en guerre que de vacciner les enfants contre les maladies infantiles [7]. Cette information est délicate à interpréter, mais, d'une part l'éradication de la poliomyélite, plusieurs fois annoncée, ne semble pas encore acquise et, d'autre part, les échos reçus des campagnes de vaccination contre la peste bovine semblent indiquer qu'elles n'ont sans doute pas donné lieu aux exactions malheureusement survenues lors de campagnes de vaccination contre des maladies infantiles (des vaccinateurs ont été assassinés). Deux ans après l'éradication de la peste bovine, les mêmes revues signalent que la recherche sur le virus se poursuit en tant que modèle de laboratoire [2]. Ceci doit rester très encadré. Une des questions posées concerne la mise au point d'un vaccin contre un virus proche responsable d'une autre maladie de l'élevage, la peste des petits ruminants. Si le même vaccin pouvait protéger contre les deux maladies, on pourrait ne garder que le virus de la peste des petits ruminants, nettement moins dangereux que celui de la peste bovine.

Au niveau gestion, on peut aussi signaler que la lutte contre la peste bovine a commencé à structurer les services nationaux en charge des questions de la santé animale dans les pays de l'Europe de l'Ouest [8], même si la mise en place des services vétérinaires au $\mathrm{XX}^{\mathrm{e}}$ siècle est plus liée à la lutte contre la fièvre aphteuse, plus contagieuse mais médicalement moins grave que la peste bovine [3].

Toute comparaison d'une maladie à une autre ou extrapolation d'une époque à une autre doit se faire avec discernement. Mais l'éradication de la peste bovine est un modèle riche d'enseignements pour le contrôle des épidémies qui intéresse non seulement les sciences médicales et vétérinaires mais également l'histoire des sciences et les sciences humaines.

\section{Références}

1. Blancou J. (2000) Histoire de la surveillance et du contrôle des maladies animales transmissibles. OIE, Paris, $366 \mathrm{p}$.

2. Butler D. (2013) Rinderpest research restarts. Nature 499(7458): 264-5

3. Conseil général vétérinaire (2006) Histoire des services vétérinaires français. Association amicale du Conseil général vétérinaire, Paris, $477 \mathrm{p}$.

4. Gilbert N. (2009) Cattle disease faces total wipeout. Nature 462(7274):709

5. Mariner JC, House JA, Mebus CA, et al (2012) Rinderpest eradication: appropriate technology and social innovations. Science 337(6100):1309-12

6. Njeumi F, Taylor W, Diallo A, et al (2012) The long journey: a brief review of the eradication of rinderpest. Rev Sci Tech 31(3): 729-4

7. Normile D. (2008) Rinderpest. Driven to extinction. Science 319(5870):1606-9

8. Vallat F (2009) Les bœufs malades de la peste. La peste bovine en France et en Europe. XVIII ${ }^{\mathrm{e}}$-XIX ${ }^{\mathrm{e}}$ siècle. Presses Universitaires de Rennes, Rennes, 360 p. 